\title{
Donor's Perspectives on Blood Donation During Covid-19 Pandemic
}

\author{
Parmatma Prasad Tripathi $^{1} \cdot$ Vijay Kumawat $^{1}$ KD $_{\text {G }}$ Gopal Kumar Patidar $^{2}$
}

Received: 30 June 2021 / Accepted: 20 November 2021/Published online: 30 November 2021

(C) Indian Society of Hematology and Blood Transfusion 2021

\begin{abstract}
Covid-19 pandemic had affected transfusion services including recruitment of donors and blood donation camps activities. The blood donors may have concerns, confusion, and misleading rumours about blood donation during pandemic. People's priorities for blood donation may shift because of a dearth of necessities. It is important to identify factors which prevent or motivate blood donors during pandemic. This study was designed to understand blood donors' knowledge, attitudes, and perceptions during the Covid-19 pandemic. A descriptive cross-sectional study to assess donor's knowledge, attitude, and perception regarding blood donation using self-administered 20 questions. The study duration was 4 months. A total 503 whole blood donors participated. The fear of infection and reduced blood donor motivation were observed to be the major deterrents of blood donation activity. Environment of blood donation area and travel to blood donation site were perceived two major sources of Covid-19 infection by participants. The top 3 motivational factor for blood donation were direct patient request to donate (30\%), followed by family/ friends need and social media campaigns ( $26 \%$ each). Most donors (70.6\%) were aware of importance of Covid-19 appropriate behaviour during current pandemic. The 67\% donors felt that adequate Covid-19 preventive measures had been followed by the staff involved in blood collection.
\end{abstract}

Vijay Kumawat

kumawatdrvijay@gmail.com

1 Department of Transfusion Medicine and Haematology, National Institute of Mental Health and Neurosciences, Bengaluru 560029, India

2 Department of Transfusion Medicine, All India Institute of Medical Sciences, New Delhi 110001, India
Based on the survey results, the inferences are that donors may harbour fear of infection and concerns for their safety, deterring blood donation. The direct appeal from a patient's relative to donate blood or a requirement in their family/friends and social media appeals emerge important factors to motivate donors. Travel facility arrangement may aide blood donation. Most of the donors are more than satisfied with the blood donation experience and are motivated to inform the transfusion services of any appearance of Covid-19 symptoms post donation. The donors were satisfied with the steps to reduce Covid-19 infection.

Keywords Blood donors - Blood donation - Covid-19 . Knowledge $\cdot$ National guidelines

\section{Introduction}

Transfusion therapy is an integral part of modern clinical practice. Blood transfusions are needed during many medical emergencies such as postpartum haemorrhage, trauma, planned major surgical procedures, organ transplant surgeries, complicated malignancies, and management of blood disorders such as thalassemia, haemophilia and sickle cell anaemia. The Coronavirus disease 2019 (Covid-19) pandemic, caused by severe acute respiratory syndrome coronavirus 2 (SARS-CoV-2), has generated widespread instability in the global healthcare system, including transfusion facilities [1]. The Covid-19 pandemic has brought unprecedented challenges in maintaining blood component inventory, as community and hospital activities have switched from their usual to more pandemic-oriented operations [2]. One of the critical aspects governing a country's blood supply is the number of blood donors [3]. 
The blood centres worldwide are finding it challenging to motivate and recruit potential blood donors and organize blood donation camps [4]. Initially, any new or re-emerging outbreak resulted in a slew of effects, like insufficient epidemiologic data. There may be inadequate communication from public health agencies and abundant misinformation that keeps circulating on social media. These factors have the potential to cause anxiety and hysteria in the general population [5]. There is a possibility for blood donors to have concerns, confusion, and misleading rumours about blood donation during the current pandemic. The government's interventions, such as home sheltering, mass lockdown, and curtailment strategies towards public gatherings, have made it difficult to organize voluntary blood donation camps (VBDCs) [6]. People's priorities may shift because of a dearth of necessities, as well as dwindling finances and limited social connections, leading them to underestimate the need for blood donation [7]. The perceived susceptibility to infection has been reported to be associated and predictor of donor intention to donate, attitude of the donor and his/ her beliefs [8]. Public knowledge assessment is an essential tool for identifying gaps and strengthening ongoing prevention efforts. Public awareness and knowledge with deeper insights into existing perception and gained practice help identify attributes of adopting healthy practice and responsive behaviour [9]. It is essential to identify factors that prevent or motivate blood donors to donate blood to support those in need. This study aimed to understand better blood donors' knowledge, attitudes, and perceptions of blood donation activities during the Covid-19 pandemic.

\section{Material and Methods}

The present descriptive cross-sectional study was performed at a blood centre of a tertiary care hospital in south India from September 2020 to January 2021 after approval from the institute ethics committee (IEC/ BS \& NS) Div./ 25th meeting/2020 dated 11-06-2020). This survey was conducted on consecutive blood donors who consented to participate and donated whole blood at our centre during the study period. All participants provided informed consent.

The sample size was calculated based on our annual collection of 2019 (6500 per year) before the Covid-19 pandemic with a $95 \%$ confidence interval and $5 \%$ margin of error. The resultant sample size was in the range of 365 to 385 . We added $10 \%$ for possible incomplete survey responses and rounded sample size to 500 with a $4.38 \%$ margin of error. The power of the study was 0.8 .

Twenty pre-structured questionnaires were used to assess donors' knowledge, attitude, and perception regarding blood donation during the Covid-19 pandemic. The survey questionnaire was prepared by the first two authors of this study, who are trained in donor recruitment and retention considering content validity. It was validated by two independent subject experts and the third author of this study and revised by Delphi technique to finalize it. The questions were designed to assess the blood donor's knowledge regarding blood demand and national guidelines for donating blood during the Covid-19 pandemic. It was also about donors' concern about the safety of blood donation in blood donation centres or VBDCs during pandemics. The questions regarding VBDC activities were included to understand the perception of donors towards healthcare activities at or near their residential premises and identify limiting factors.

We also inquired about their current blood donation experience and safety measures taken by blood bank staff. Finally, questions about their knowledge in view of transfusion transmissibility of SARS-Cov-2 virus and their willingness to notify the blood centre if they become infected after donation were included in the questionnaire.

The blood donors were selected as per the Drugs and Cosmetic Acts and Rule 1945 (recent amendment, March 2020) and national guidance to blood transfusion services in light of the Covid-19 pandemic issued by the national blood transfusion council (NBTC) [10, 11]. As per NBTC guidelines, five Covid-19 screening questions, including symptoms of Covid-19, recent close contact history, previous history of Covid-19 infection, recent international travel and whether donor residence locality was declared containment zone were added to whole blood donor questionnaire and consent form before blood collection to ascertain the risk of Covid-19 infection. The Covid-19 appropriate behaviour, including the use of mask and mask etiquettes, frequent hand sanitation, and social distancing, were displayed in the donor registration area as a part of awareness for preventing Covid-19. Likert scale [12] was used for few questions. The anxiety was graded according to the anxiety Likert scale validated previously by Davie [13]. The printed questionnaire (20 questions) was selfadministered by donors after successful blood donation at hospital premises to record their responses. The process for donor inclusion in the study is shown in Fig. 1

\section{Data Collection and Analysis}

The donor's demographic details were obtained from blood donor questionnaire and consent form for whole blood donation. The responses to the questions were recorded in a master Microsoft excel sheet (Microsoft, Redmond, WA, USA) and analysed. Percentage values were calculated by using the total consented donor as the denominator. 


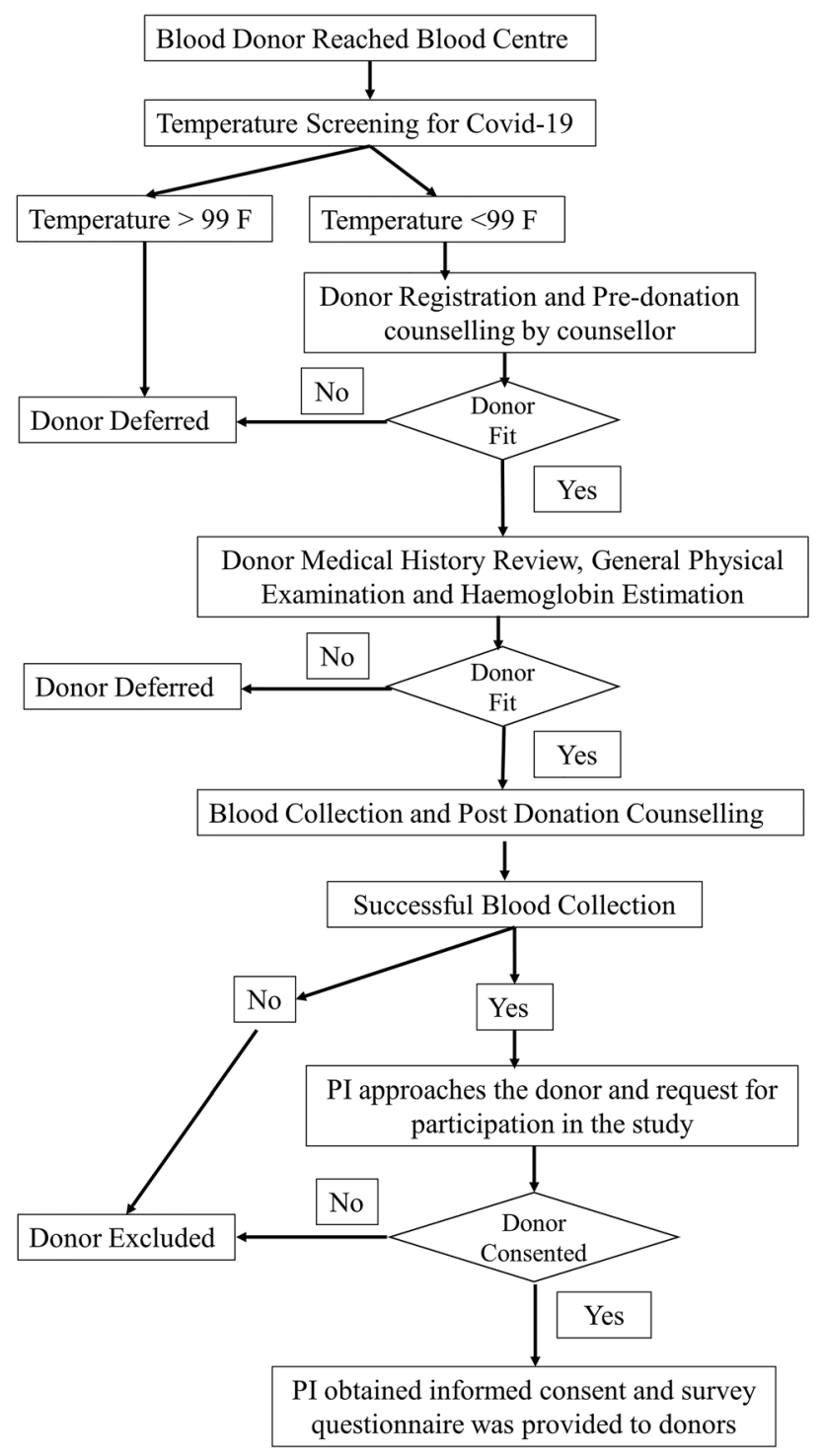

Fig. 1 The process for donor inclusion in the study

\section{Results}

The 1796 whole blood (WB) donors donated during four months study period at our centre (September 2020 to January 2021) compared to $2780 \mathrm{WB}$ donors before the Covid-19 pandemic during these months (September 2019 to January 2020). A total of 503 WB donors who consented were included in this study predominantly $(98.4 \%)$ male. The demographic information of study population is presented in Table 1.

The detailed results of donors' knowledge are provided in Table 2. The $350(69.6 \%)$ donors were aware of the shortage of blood during the Covid-19 pandemic. The 263 (52.3\%) accepted that there was a constant requirement of blood even during the current pandemic, only $66(13.1 \%)$ of donors did not agree with constant blood requirement,
Table 1 Demographic of study population $(n=503)$

\begin{tabular}{lc}
\hline Demographics & $\mathrm{n}(\%)$ \\
\hline Age range & \\
18-29 years & $272(54.1)$ \\
$30-39$ years & $173(34.4)$ \\
$40-49$ years & $50(9.9)$ \\
More than 50 & $8(1.6)$ \\
Gender & \\
Male & $495(98.4)$ \\
Female & $8(1.6)$ \\
Type of donors & $273(54.3)$ \\
Voluntary donors & $230(45.7)$ \\
Replacement donors & \\
Donation status & $239(47.5)$ \\
First time donors & $264(52.5)$ \\
Repeat donors &
\end{tabular}

and $175(34.6 \%)$ were either not sure or did not know. The $15.7 \%$ of participants feel that Covid-19 can be transmitted through donated blood, $43.1 \%$ denied while the remaining $41.1 \%$ were either unsure or did not know. The 205 $(40.7 \%)$ donors were aware of national guidelines for blood donation during the current pandemic to ensure the safety of donors and recipients.

The fear of infection resulting in reduced voluntary blood donation drives and reduced blood donor motivation were observed to be the major deterrents of blood donation activity during the Covid-19 pandemic (Fig. 2a). The environment of the blood donation area followed by travel were perceived as the two major sources of Covid-19 infection during blood donation activity by participants (Fig. 2a). Most donors (57.1\%) had anxiety for Covid-19 infection, while $2.5 \%$ reported extremely high anxiety (Fig. 2b). Despite the anxiety, $53.1 \%$ of donors were definitely willing to donate, while only $7.4 \%$ did not want to donate. (Fig. 2b).

The donors gave varied responses regarding the safety of blood donation and organizing VBDCs (Table 2). A total of $42 \%$ of donors did not believe that VBDCs teams could spread Covid-19 during their community blood collection drives. The hospital-based blood donation centre was the preferred choice to donate blood compared to standalone blood centres and VBDCs (Fig. 3a). Around $60 \%$ of donors were willing to help organise VBDCs, but $1 / 3$ expressed willingness with neighbour/ office colleague consent (Fig. 3a). Most donors (70.6\%) were aware of the importance of Covid-19 appropriate behaviour during the current pandemic. The $67 \%$ of donors felt that adequate Covid- 19 
Table 2 Donor's knowledge of blood donation during Covid-19 pandemic

\begin{tabular}{llllll}
\hline Sr. No & Survey questions & \multicolumn{2}{l}{$\begin{array}{l}\text { Responses } \\
\mathrm{n}(\%)\end{array}$} & \multicolumn{2}{l}{} \\
\cline { 3 - 6 } & & Yes & No & I am not sure & I don't know \\
\hline 1 & Are you aware for shortage of blood due to Covid-19 pandemic? & $350(69.6)$ & $153(30.4)$ & NA & NA \\
2 & There is constant requirement of blood during Covid-19 pandemic? & $263(52.3)$ & $66(13.1)$ & $129(25.6)$ & $45(9.0)$ \\
3 & Do you think that COVID-19 can spread through your donated blood? & $79(15.8)$ & $217(43.1)$ & $156(31)$ & $51(10.1)$ \\
4 & Is it safe to donate blood during Covid-19 pandemic? & $255(50.7)$ & $90(17.9)$ & $135(26.8)$ & $23(4.6)$ \\
5 & Is it safe to organize VBDC during Covid-19 pandemic? & $183(36.4)$ & $98(19.5)$ & $195(38.8)$ & $27(5.3)$ \\
6 & Are you aware of national guidelines for blood collection & Yes & No & I heard but not aware completely \\
& during COVID-19 in India? & $205(40.8)$ & $165(32.8)$ & $133(26.4)$
\end{tabular}

preventive measures had been followed by the staff involved in blood collection (Fig. 3b).

Majorly $(56.7 \%)$ donors rated their blood donation experience despite the pandemic as excellent (Table 3). Only $36.8 \%$ of donors felt that transport facilitation by blood centres for blood donors positively affects their blood donation decision (Table 3 ). The majority of $(70 \%)$ donors were willing to inform the blood centre if they developed symptoms or were diagnosed infected with Covid-19 (Table 3). The top 3 motivational factors for blood donation were direct patient request to donate, followed by family/ friends need and social media campaigns (Table 3). The most common reason for the current donation was family member/ friend need of blood $(57.9 \%$ responses) followed by motivation due to shortage of blood (27.8\% responses), and donor felt the responsibility to donate $(22.5 \%$ responses $)$.

\section{Discussion}

The majority of participants in this study were male, similar to gender distribution reported by the world health organization (WHO) and from other Asian countries $[14,15]$. The blood collection at blood centres reduced considerably worldwide due to the Covid-19 pandemic $[2,3,7]$. Almost half of the donors (47.5\%) during the study period were first time WB donors. This is similar to the study in the Netherlands reporting increase in new donor registration during the Covid-19 pandemic [16]. Donors who come forward to help following a disaster are likely to be first-time donors or previously lapsed donors, which may be the case with Covid-19. The transfusion services should retain first-time donors to sustain blood supply considering the long duration of this pandemic [17]. A good proportion of the donors were aware of the blood shortage during the pandemic, and more than $50 \%$ accepted the constant need for blood. This is similar in line with reported increased general awareness for blood donation during the Covid-19 pandemic [16].

Transfusion transmission of the SARS-CoV-2 virus is yet to be determined. In this study, $43.1 \%$ of donors believed that SARS-CoV-2 virus transmission through transfusion was unlikely compared to a study in Cameroon, in which $74.9 \%$ of donors claimed that Covid-19 could be transmitted to blood recipients [18]. The Indian national regulatory agencies issued recommendations for accepting blood donations and organizing VBDC during the Covid19 pandemic [11]. We surveyed blood donors' awareness and attitudes toward blood donation during the pandemic timeframe for this study. $40 \%$ of donors were aware of the national guidelines. The unawareness of these guidelines among the majority may be attributed to the lack of publicity and access to specialised websites that are not well recognised beyond scientific communities and healthcare workers. The clinical governance principle to improve healthcare quality advocates patient participation in their care plan by making them reasonably aware [19]. The same principle can be applied to the donors to create awareness of their eligibility, deferral criteria, and national guidelines to improve their participation, resulting in improved trust and better transfusion services. It is advisable to raise public consciousness about national guidelines. It can be achieved by print, social media, blood centres, or nongovernmental organisations (NGOs) launching awareness campaigns. The knowledge of national guidelines available to guide transfusion services for adapting to new normal may assure donors and build their confidence in transfusion services.

According to the study participants, most people were hesitant for blood donation due to fear of infection. Previous studies have also identified fear as the most common impediment to blood donation [18, 20, 21]. A recent study from India also reported fear of infection as a single most important deterrent for blood donation [22]. A fear among donors during viral epidemics impacting transfusion services is not new to Covid-19 [5, 8], and the perceived risk 
Fig. 2 a Deterrents of blood donation activity and perceived source of Covid-19 infection during blood donation activity. b Blood donor's anxiety for Covid-19 infection and their willingness to continue blood donation during pandemic VBDCs at their residential locality/office (a) Perceived source of Covid-19 infection during blood donation activity

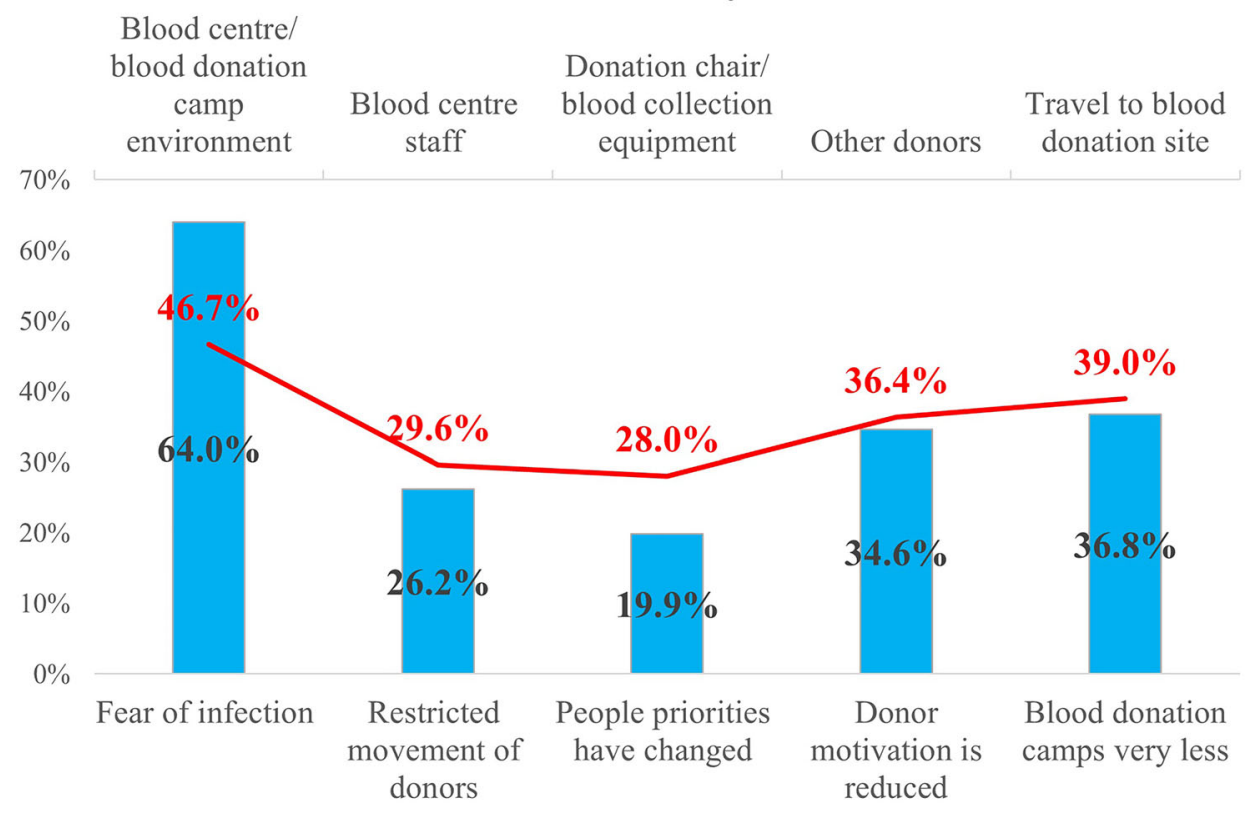

Deterrent of blood donation activity during Covid-19 pandemic

(b) Donor's willingness to donate blood during Covid-19 pandemic

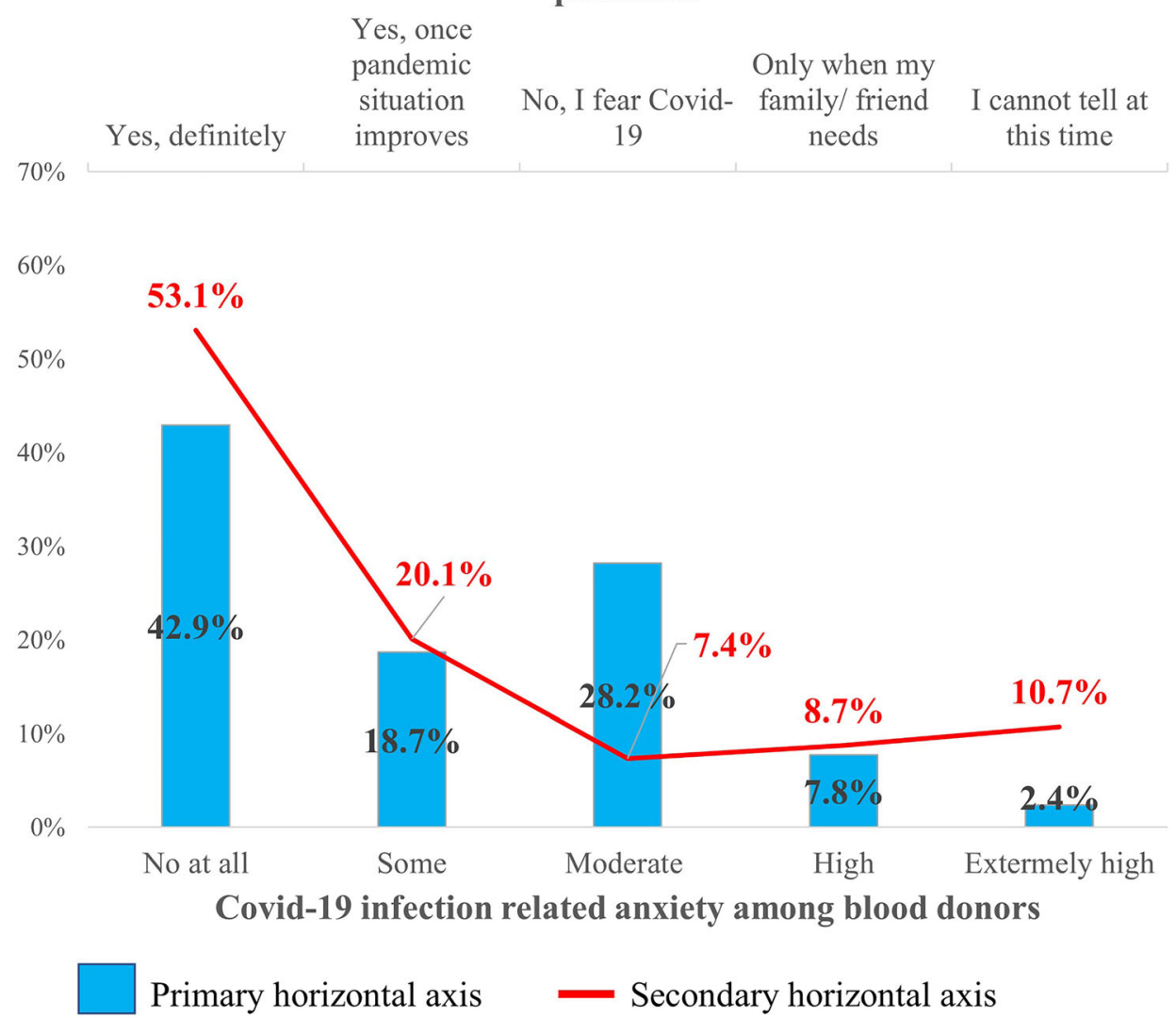
pandemic situation improves $20.1 \%$ Secondary horizontal axis 
Fig. 3 a Preferred choice of location for blood donation and donor's willingness to help to organize VBDCs at their residential locality/office. b Need and adequacy of Covid19 appropriate behaviour \& preventive measures by blood centre staff and donors (a) Organizing VBDCs at donor's residential locality/ office

$$
\text { Yes, provided Yes, but }
$$$$
\text { my neighbour community/ }
$$

Yes, I would like and/ or office office colleague to do colleagues agree will not agree Not Sure Not at all $70 \%$

$60 \%$

$50 \%$

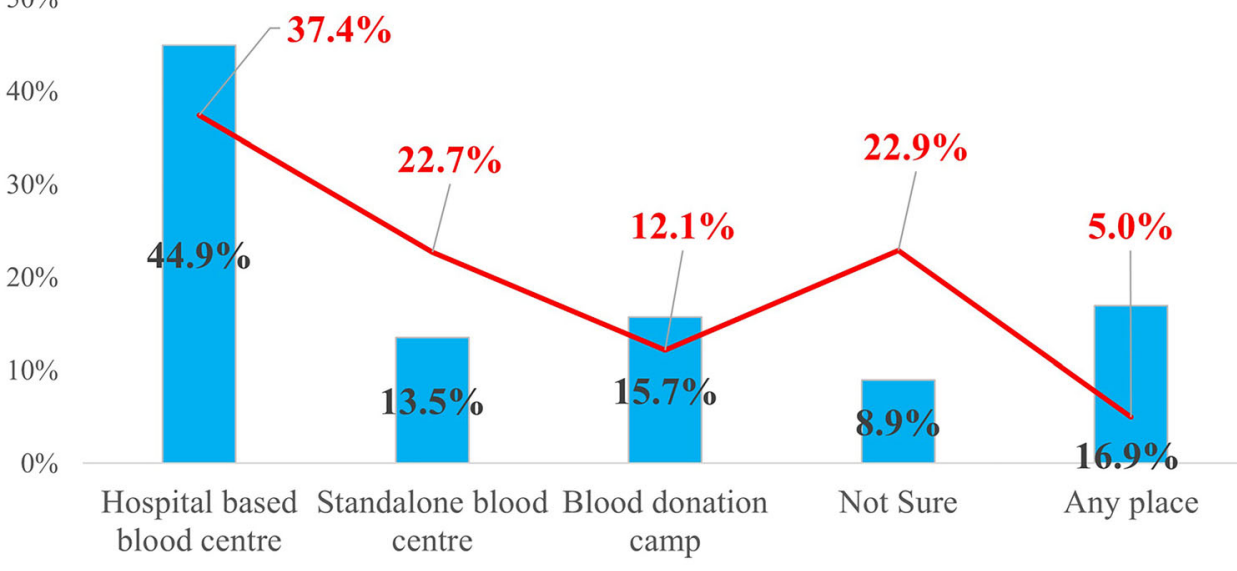

Preferred location for blood donation during pandemic

(b) Adequacy of Covid preventive measures by blood centre staff Disagree strongly

Disagree

Undecided

Agree

Agree strongly

$80 \%$

$70 \%$

$60 \%$

$50 \%$

$40 \%$

$\quad 70 \%$

$30 \%$

$20 \%$

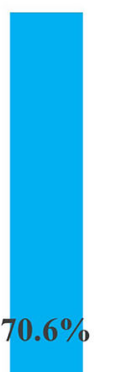

$10 \%$

$0 \%$

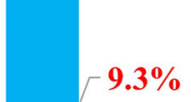

$15.7 \%$

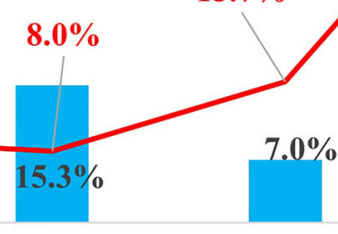

$5.3 \%$

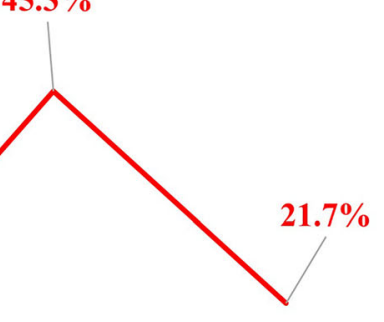

$5.0 \%$

$2.2 \%$

Yes, it is very Should be Not required Can't comment Do not know important personal choice

Need of Covid appropriate behaviour by donor and staff

Primary horizontal axis Secondary horizontal axis 
Table 3 Donor's perception and response to blood donation during Covid-19 pandemic

\begin{tabular}{|c|c|c|c|}
\hline Sr. No & Survey questions & & $\begin{array}{l}\text { Responses } \\
\mathrm{n}(\%)\end{array}$ \\
\hline \multirow[t]{5}{*}{1} & \multirow[t]{5}{*}{ What would appeal you most to donate blood? } & Patient relative requesting to donate & $149(29.6)$ \\
\hline & & Social media campaign for blood donation & $131(26)$ \\
\hline & & Your close family member/ friends require blood & $129(25.7)$ \\
\hline & & Appeal by a public figure or celebrity & $56(11.1)$ \\
\hline & & NGOs working for blood donation contacting you & $38(7.6)$ \\
\hline \multirow[t]{5}{*}{2} & \multirow{5}{*}{$\begin{array}{l}\text { If pick and drop facility from your home is provided by } \\
\text { blood bank, how would it make a difference? }\end{array}$} & Yes, encourages me to donate & $185(36.8)$ \\
\hline & & Not sure about its effect & $156(31)$ \\
\hline & & Does not affect my decision to donate blood & $94(18.7)$ \\
\hline & & I would prefer my own vehicle & $64(12.7)$ \\
\hline & & Do not want to donate again & $4(0.8)$ \\
\hline \multirow[t]{5}{*}{3} & \multirow{5}{*}{$\begin{array}{l}\text { How would you rate your current donation compared } \\
\text { to before COVID-19 }\end{array}$} & Excellent & $285(56.7)$ \\
\hline & & Above average & $90(17.9)$ \\
\hline & & Average & $108(21.5)$ \\
\hline & & Below average & $14(2.7)$ \\
\hline & & Poor & $6(1.2)$ \\
\hline \multirow[t]{5}{*}{4} & \multirow{5}{*}{$\begin{array}{l}\text { After your donation if you develop symptoms } \\
\text { of COVID-19, would you prefer to inform blood bank? }\end{array}$} & Definitely & $352(70)$ \\
\hline & & Very probably & $63(12.5)$ \\
\hline & & Possibly & $68(13.5)$ \\
\hline & & Probably not & $11(2.2)$ \\
\hline & & Definitely not & $9(1.8)$ \\
\hline
\end{tabular}

of infection among donors did not vary from non-donors [23]. A lack of motivation and a smaller number of VBDCs, and travel restrictions due to government lockdown and financial crisis also contributed to the same. It is normal to fear the unknown, especially if it affects our and our family members' health and has been reported in the general population and health professionals impacting their lives [24-26]. The diminishing finances and restricted social interactions may alter donors' intention to donate blood [7]. The donor's concern for the safety of blood donation and VBDCs reflect generalized uncertainty during the pandemic, which multiply continuously for individuals and policymakers [27]. This uncertainty can be attributed to the fact that scientific evidence is still uncertain, emergent, and evolving [28]. The dissemination of inaccurate scientific information, coupled with misleading rumours that has the potential to grow exponentially, can become sources of fear, prejudice, and inappropriate behaviour [29].

Regarding safety during blood donation, around $50 \%$ of blood donors felt safe themselves at the of blood donation and had excellent experience during their current donation. They would like to donate blood voluntarily after 3-4 months, even in the same pandemic situation. This can be attributed to the fact that those who fear more for infection are very less likely to become blood donors as reported earlier [30]. The association between Covid-19 related thoughts, intention for blood donation and behaviour are reported to be more complex than just a fear or perceived risk deferring donors to donate [23]. The fact that blood donation could involve some risk to the donor thus inducing fear and awaiting others to consent appear to play a key role in determining intention to donate [8]. The motivation for contribution to public health has also been reported as a factor determining donor registration and subsequent donation [16].

Forty-five percent of the participants felt safe donating blood at blood centres in comparison to VBDC drives. Almalki et al. had described that $65 \%$ of participants preferred mobile blood collection sites for blood donation [15]. This is different from our study findings, where only $15 \%$ had preferred VBDC for blood donation. It is easy to maintain hygiene and social distancing in blood centres compared to VBDC drives. Our tertiary care hospital, which was not involved in direct Covid-19 patient care, may also be one of the reasons for the donor to donate at our blood centre. More than $70 \%$ of respondents believed it is important to take safety precautions like social distancing, hand hygiene, and wearing a mask by blood centre staff and blood donors. Around $65 \%$ believed that blood centre staff take these safety precautions. This is in concurrence with $70 \%$ satisfaction of participants with the 
measures initiated to reduce Covid-19 infection [15]. The staff adherence to the Covid related protocol during blood collection and post-donation care helped gain donors' confidence. The blood collection facility has been advised to ensure steps to reduce infection risk, which can help achieve donors' trust [30]. Despite this, almost $40 \%$ of respondents were not sure of organising VBDC drives in this pandemic, probably due to safety issues. Although $60 \%$ of respondents agreed to help organise VBDC drives, mainly because most did not believe that VBDC staff of blood centres can transmit the infection to the community, one-third of them put forth the condition of acceptance by their society or office colleagues. Healthcare workers (HCWs) are often stigmatized as a source of infection during a widespread outbreak of infectious diseases. The HCWs were feared, avoided, shunned, and ostracized by communities to fear that HCWs were infected with Covid19 as potential sources of infection [31, 32].

More than $80 \%$ of donors in our study were willing to notify blood centres if they experienced Covid-19 symptoms within 14 days of donating blood. It suggests that donors were concerned with those who will receive donated blood, which is close to the response-efficacy of coping assessment [23].

On the motivational front, the patients/ relatives approaching with blood donation request followed by family/ friend need and social media appeal were the three main motivating factors for blood donation. This signifies that if important people to donor approve blood donation, chances of blood donation are stronger [8]. Social media now plays an increasingly significant role in communicating information and news [24]; However, McFadden reported social media as the least trusted source of information. Still, social media has been reported as an important donor recruitment tool in recent times, both before and during the current pandemic [33, 34]. The new donor registration peaks in the Netherlands coincided with an appeal for blood donation in social and print media [16]. Social media was the preferred mode of information source during the Covid-19 pandemic in Saudi Arabia [15]. It can also be boosted by government assistance in ensuring complimentary and hassle-free transportation of blood donors via public transportation or staff vehicles. The appeal by a public figure or celebrity did not seem to affect donation decisions in most donors. Politically motivated actions such as seeking to downplay or dismiss the risks of exposure to Covid-19 creates distrust [24]. This may be the possible reason for not getting influenced by public figures.

The most important emphasis should be to provide comprehensive public health knowledge about the disease and its transmission mechanisms [18, 32]. The blood centres should build and maintain trust on a priority basis through sincere communications based on truth and scientific facts that assure blood donor well-being [23]. This can enhance coping appraisals, including self-efficacy, determining intention to donate [23].

\section{Conclusion}

Based on the survey results, the inferences are that donors may harbour fear of infection and concerns for their safety, deterring blood donation. The direct appeal from a patient's relative to donate blood or a requirement in their family/friends and social media appeals emerge important factors to motivate donors. Travel facility arrangement may aide blood donation. Most of the donors are more than satisfied with the blood donation experience and are motivated to inform the transfusion services of any appearance of Covid-19 symptoms post donation. The donors were satisfied with the steps to reduce Covid-19 infection.

\section{Limitation of the Study}

Our study majorly included donors who donated blood at the blood centre due to less frequent VBDC drives during Covid-19 times. The study participants were blood donors with no control group from the general population, which may have provided better insight and responses to few questions got biased. The survey questionnaire was provided to the donors after completing their blood donation, which may have a confounding effect on survey responses. The participants' responses might have been biased due to pandemic related changes in day to day living.

Supplementary InformationThe online version contains supplementary material available at https://doi.org/10.1007/s12288021-01504-y.

Acknowledgements We sincerely thanks Mrs. Beena A.T, Mrs. Arogya Mary and Mr. N. Shivanna for encouraging donors to participate in this study. We Sincerely acknowledge support, mentorship, and guidance of Professor Vani Santosh.

Authors Contribution PPT: Conceptual design literature search, data compilation, manuscript review. VK: Conceptual design literature search, data compilation, manuscript preparation and editing, manuscript review, guarantor. GKP: Manuscript preparation and editing, manuscript review.

Funding Not applicable.

Availability of Data and Materials The original data is available with the corresponding author.

\section{Declarations}

Conflict of interest The authors declare that they have no conflicts of interest relevant to the manuscript submitted to journal. 
Ethics Approval Study was approved by institute ethics committee dated 11-06-2020.

Consent to Participate An informed consent was obtained from all participants prior to study enrollment.

Consent to Publication All authors have approved the manuscript and consented for publication.

\section{References}

1. Stanworth SJ, New HV, Apelseth TO, Brunskill S, Cardigan R, Doree C, Germain M et al (2020) Effects of the COVID-19 pandemic on supply and use of blood for transfusion. Lancet Haematol 7(10):e756-e764. https://doi.org/10.1016/S23523026(20)30186-1

2. Pagano MB, Hess JR, Tsang HC, Staley E, Gernsheimer T, Sen N et al (2020) Prepare to adapt: blood supply and transfusion support during the first 2 weeks of the 2019 novel coronavirus (COVID-19) pandemic affecting Washington State. Transfusion 60(5):908-911. https://doi.org/10.1111/trf.15789

3. Pandey HC, Coshic P, Chippy CS, Arcot PJ, Kumar K (2020) Blood supply management in times of SARS-CoV-2 pandemicchallenges, strategies adopted, and the lessons learned from the experience of a hospital-based blood centre. Vox Sang 116(5):497-503. https://doi.org/10.1111/vox.13019

4. Vassallo RR, Bravo MD, Kamel H (2021) Pandemic blood donor demographics - do changes impact blood safety? Transfusion 61(5):1389-1393. https://doi.org/10.1111/trf.16320

5. Shan H, Zhang P (2004) Viral attacks on the blood supply: the impact of severe acute respiratory syndrome in Beijing. Transfusion 44(4):467-469. https://doi.org/10.1111/j.0041-1132.2004. 04401.x

6. Sahu KK, Raturi M, Siddiqui AD, Cerny J (2020) "Because every drop counts": blood donation during the COVID-19 pandemic. Transfus Clin Biol 27(3):105-108. https://doi.org/10.1016/j.tra cli.2020.06.009

7. Kumar S, Azim D, Nasim S, Hashmi SH (2020) Dwindling blood reserves: an ominous downside of COVID-19 pandemic. Transfus Apher Sci 59(5):102818. https://doi.org/10.1016/j.transci. 2020.102818

8. Masser BM, White KM, Hamilton K, McKimmie BM (2011) An examination of the predictors of blood donors' intentions to donate during two phases of an avian influenza outbreak. Transfusion 51(3):548-557. https://doi.org/10.1111/j.1537-2995. 2010.02887.x

9. Podder D, Paul B, Dasgupta A, Bandyopadhyay L, Pal A, Roy S (2019) Community perception and risk reduction practices toward malaria and dengue: a mixed-method study in slums of Chetla. Kolkata Indian J Public Health 63(3):178-185. https:// doi.org/10.4103/ijph.IJPH_321_19

10. 2020.18.03_Final G.S.R. 166(E)_Amendment in Part X B \& Part XII B pertains to Blood centre and Blood components, Ministry of health \& family welfare, Government of India. Available at: https://cdsco.gov.in/opencms/opencms/en/Notifications/GazetteNotifications/. Assessed on May 04, 2021

11. 2nd Interim National Guidance to Blood Transfusion Services in India in light of COVID-19 Pandemic. Available at https:// covid19.india.gov.in/document/2nd-interim-national-guidanceto-blood-transfusion-services-in-india-in-light-of-covid-19-pan demic/. Assessed on May 04, 2021

12. Bishop PA, Herron RL (2015) Use and misuse of the likert item responses and other ordinal measures. Int $\mathrm{J}$ Exerc Sci 8(3):297-302
13. Davey HM, Barratt AL, Butow PN, Deeks JJ (2007) A one-item question with a Likert or Visual Analog Scale adequately measured current anxiety. J Clin Epidemiol 60(4):356-360. https:// doi.org/10.1016/j.jclinepi.2006.07.015

14. Gender distribution of blood donors, by country. Available at https://www.who.int/worldblooddonorday/media/blood_donors_ gender_distribution_2011.pdf. Assessed on October 10, 2021

15. Almalki S, Asseri M, Khawaji Y, Alqurashi R, Badawi M, Yakout N, Elgemmezi T, Hindawi S (2021) Awareness about Coronavirus (COVID-19) and challenges for blood services among potential blood donors. Transfus Apher Sci 6:103211. https://doi.org/10.1016/j.transci.2021.103211

16. Spekman MLC, Ramondt S, Quee FA, Prinsze FJ, Huis In 't Veld EMJ, van den Hurk K, Merz EM (2021) New blood donors in times of crisis: Increased donation willingness, particularly among people at high risk for attracting SARS-CoV-2. Transfusion 61(6):1822-1829. https://doi.org/10.1111/trf.16334

17. Haw J, Holloway K, Masser BM, Merz EM, Thorpe R (2021) Blood donation and the global COVID-19 pandemic: areas for social science research. Vox Sang 116(4):363-365. https://doi. org/10.1111/vox.12974

18. Tagny CT, Lendem I, Ngo Sack F, Ngo Balogog P, Ninmou C, Dongmo A et al (2020) Trends in blood donations, blood donors' knowledge, practices and expectations during the COVID-19 pandemic in Cameroon. Vox Sang 116(6):637-644. https://doi. org/10.1111/vox.13049

19. Mastaneh Z, Mouseli L (2013) Patients' awareness of their rights: insight from a developing country. Int $\mathbf{J}$ Health Policy Manag 1(2):143-146. https://doi.org/10.15171/ijhpm.2013.26

20. Wang Y, Han W, Pan L, Wang C, Liu Y, Hu W et al (2020) Impact of COVID-19 on blood centres in Zhejiang province China. Vox Sang 115(6):502-506. https://doi.org/10.1111/vox. 12931

21. Dhiman Y, Coshic P, Pandey HC, Khatiwada B, Singh J, Mehta $\mathrm{V}$ et al (2021) Deterrents in recruitment of COVID-19 convalescent plasma donors: Experience from a hospital-based blood centre in India. Transfus Med 31(3):149-154. https://doi.org/10. 1111/tme. 12768

22. Sachdev S, Kishore K, Singh L, Lamba DS, Hans R, Dhawan HK, Grover S, Sharma RR (2021) Exploration of COVID-19 related fears deterring from blood donation in India. ISBT Sci Ser 16(2):147-157. https://doi.org/10.1111/voxs.12623

23. Masser BM, Hyde MK, Ferguson E (2020) Exploring predictors of Australian community members' blood donation intentions and blood donation-related behavior during the COVID-19 pandemic. Transfusion 60(12):2907-2917. https://doi.org/10.1111/ trf. 16067

24. $\mathrm{Ng} \mathrm{KH}, \mathrm{Kemp} \mathrm{R}$ (2020) Understanding and reducing the fear of COVID-19. J Zhejiang Univ Sci B 21(9):752-754. https://doi. org/10.1631/jzus.B2000228

25. Hossain MA, Jahid MIK, Hossain KMA, Walton LM, Uddin Z, Haque MO et al (2020) Knowledge, attitudes, and fear of COVID-19 during the Rapid Rise Period in Bangladesh. PLoS ONE 15(9):e0239646. https://doi.org/10.1371/journal.pone. 0239646

26. Gasparro R, Scandurra C, Maldonato NM, Dolce P, Bochicchio V, Valletta A et al (2020) Perceived job insecurity and depressive symptoms among Italian dentists: the moderating role of fear of COVID-19. Int J Environ Res Public Health 17(15):5338. https:// doi.org/10.3390/ijerph17155338

27. Rutter H, Wolpert M, Greenhalgh T (2020) Managing uncertainty in the covid-19 era. BMJ 370:m3349. https://doi.org/10.1136/ bmj.m3349

28. Lancaster K, Rhodes T, Rosengarten M (2020) Making evidence and policy in public health emergencies: Lessons from COVID- 
19 for adaptive evidence-making and intervention. Evid Policy 16(3):477-490

29. Pimenta IDSF, de Sousa Mata ÁN, Braga LP, de Medeiros GCBS, de Azevedo KPM, Bezerra INM et al (2020) Media and scientific communication about the COVID-19 pandemic and the repercussions on the population's mental health: A protocol for a systematic review and meta-analysis. Medicine (Baltimore) 99(50):e23298. https://doi.org/10.1097/MD.0000000000023298

30. Chandler T, Neumann-Böhme S, Sabat I, Barros PP, Brouwer W, van Exel J, Schreyögg J, Torbica A, Stargardt T (2021) Blood donation in times of crisis: Early insight into the impact of COVID-19 on blood donors and their motivation to donate across European countries. Vox Sang. https://doi.org/10.1111/vox.13103

31. Taylor S, Landry CA, Rachor GS, Paluszek MM, Asmundson GJG (2020) Fear and avoidance of healthcare workers: an important, under-recognized form of stigmatization during the
COVID-19 pandemic. J Anxiety Disord 75:102289. https://doi. org/10.1016/j.janxdis.2020.102289

32. Bagcchi S (2020) Stigma during the COVID-19 pandemic. Lancet Infect Dis 20(7):782. https://doi.org/10.1016/S14733099(20)30498-9

33. Sümnig A, Feig M, Greinacher A, Thiele T (2018) The role of social media for blood donor motivation and recruitment. Transfusion 58(10):2257-2259. https://doi.org/10.1111/trf.14823

34. Waheed U, Wazeer A, Saba N, Qasim Z (2020) Effectiveness of WhatsApp for blood donor mobilization campaigns during COVID-19 pandemic. ISBT Sci Ser 15:378-380. https://doi.org/ 10.1111/voxs. 12572

Publisher's Note Springer Nature remains neutral with regard to jurisdictional claims in published maps and institutional affiliations. 